\title{
SELEÇÃO E USO DE ANTIBIÓTICOS EM INFECÇÕES INTRA-ABDOMINAIS
}

\author{
Júlio Cezar Uili COELHO, Giorgio Alfredo Pedroso BARETTA e Luciano OKAWA
}

\begin{abstract}
RESUMO - Racional - Infecções intra-abdominais são comuns e apresentam elevada morbidade e mortalidade e os agentes infecciosos responsáveis por tais afecções são geralmente os da flora gastrointestinal, em especial a E. coli e Bacteroides fragilis. Objetivo - Apresentar uma revisão da seleção e uso de antibióticos em infecções intra-abdominais. Conclusões - O uso adequado de antibióticos é fundamental para o controle mais rápido da infecção e reduzir a possibilidade de falha no tratamento. A terapia antimicrobiana é iniciada na suspeita de infecção intraabdominal e os agentes antibióticos selecionados são utilizados de acordo com os germes mais prováveis de serem encontrados no local da infecção. Além disso, eficácia, custo, segurança e comodidade posológica são considerados para uma seleção mais apropriada. Diferentes esquemas são utilizados em infecções intra-abdominais comunitárias e hospitalares devido à flora mais resistente destas últimas.

DESCRITORES - Abdome. Infecção. Infecção hospitalar. Agentes bacterianos.
\end{abstract}

\section{INTRODUÇÃO}

A cavidade peritonial é um espaço fechado e estéril, revestido em toda a sua extensão por células mesoteliais. Além das vísceras, a cavidade contém cerca de $50 \mathrm{~mL}$ de líquido seroso.

Essa cavidade é altamente eficaz contra infecção através de três mecanismos: 1) macrófagos residentes na cavidade, que são capazes de fagocitar e destruir grande número de agentes infecciosos; 2) absorção de líquidos e partículas, incluindo agentes infecciosos, através de linfáticos localizados na superfície peritonial do diafragma Os agentes infecciosos são transportados para o ducto torácico e a corrente sangüínea, aonde são eliminados pelos mecanismos de defesa sistêmica do organismo; 3 ) bloqueio e isolamento de um processo infeccioso pelo epíplon e as vísceras adjacentes.

A invasão e proliferação de agentes infecciosos na cavidade abdominal provocam processo inflamatório intenso. As infecções intra-abdominais difusas são denominadas de peritonite, enquanto que as que foram isoladas e limitadas pelo organismo dentro de um órgão intra-abdominal ou na cavidade peritonial são chamados de abscesso. Infecção intraabdominal complicada é definida como a infecção que se estende além da víscera oca de origem para a cavidade peritonial e é associada à formação de abscesso ou peritonite ${ }^{(29)}$.

As infecções intra-abdominais são comuns e são associadas à elevada morbidade e mortalidade, especialmente em certos grupos como idosos e imunodeprimidos. O uso apropriado de antibióticos é fundamental para reduzir essas complicações.

O objetivo do presente estudo foi apresentar revisão da seleção e uso de antibióticos em infecções intra-abdominais.
A peritonite primária, que é relacionada à disseminação de bactérias por via hematogênica ou diretamente para a cavidade abdominal, na ausência de perfuração de uma víscera oca, não será discutida.

\section{Agentes infecciosos}

Os agentes infecciosos associados às infecções intraabdominais são os da flora do trato gastrointestinal. Perfuração do trato gastrointestinal e extravasamento da sua flora para a cavidade abdominal causam peritonite secundária e ou formação de abscesso. $\mathrm{O}$ número e as espécies de agentes infecciosos aumentam ao longo do trato gastrointestinal de $10^{2}$ a $10^{3}$ bactérias por $\mathrm{mL}$ no estômago para $10^{11}$ a $10^{12}$ no intestino grosso. Na presença de obstrução intestinal, de tumores e corpo estranho, o número de bactérias aumenta expressivamente.

A flora do trato gastrointestinal consiste de bactérias anaeróbias facultativas e obrigatórias, bactérias aeróbicas gram-negativas e bactérias aeróbicas gram-positivas ${ }^{(6)}$. Infecções hospitalares são causadas por flora mais resistente, que incluem Pseudomonas aeruginosa, Enterobacter sp., Proteus sp., Staphylococcus aureus resistente à meticilina, enterococos e Candida sp. Abscessos secundários à pancreatite aguda ou infecção de pseudocistos pancreáticos também são causados pela flora do trato gastrointestinal, que alcançam o pâncreas, possivelmente, por translocação bacteriana através da parede intestinal.

\section{Materiais para cultura}

Hemoculturas não são recomendadas para pacientes com infecções comunitárias por não fornecerem informações relevantes (categoria A e grau 1 de recomendação do Quadro 1). Espécimes coletados do sítio de infecção abdominal devem 
ser representativos e não há benefícios em se coletar múltiplas amostras. Tanto culturas para aeróbios quanto anaeróbios podem ser realizadas utilizando apenas um único espécime de volume suficiente (mínimo de $0,5 \mathrm{~mL}$ de líquido ou tecido) e transportadas ao laboratório em sistema de transporte para anaeróbios. O uso de swabs deve ser evitado.

A realização do gram nos materiais coletados de infecções comunitárias também não tem valor (categoria $\mathrm{B}$ e grau $2 \mathrm{de}$ recomendação do Quadro 1). Por outro lado, em infecções nosocomiais ou pós-operatórias, a realização do gram pode ser importante para determinar a terapia específica para os germes gram-positivos meticilino-resistentes ${ }^{(23)}$. Susceptibilidade local ao $S$. aureus e Enterococcus pode justificar a adição de vancomicina ao esquema terapêutico até que os resultados das culturas estejam disponíveis.

QUADRO 1. Sistema de graduação para o grau de recomendação dos "guidelines" clínicos da Sociedade Americana de Doença Infecciosa - Serviço de Saúde Pública dos Estados Unidos

\begin{tabular}{|ll|}
\hline $\begin{array}{l}\text { Categoria, Grau } \\
\text { Categoria de Recomendação }\end{array}$ & \multicolumn{1}{c|}{ Definição } \\
\hline A & Evidência boa recomendando o uso \\
B & Evidência moderada recomendando o uso \\
C & Evidência ruim recomendando o uso \\
D & Evidência moderada não recomendando o uso \\
E & Evidência boa não recomendando o uso \\
& \\
\hline Grau da Evidência & \\
1 & Evidência de $\geq 1$ estudo adequadamente controlado e \\
& aleatório \\
2 & $\begin{array}{l}\text { Evidência de } \geq 1 \text { estudo clínico bem elaborado, não } \\
\text { aleatório; de estudos coortes ou analíticos de casos } \\
\text { controlados (preferencialmente de }>1 \text { centro); de séries } \\
\text { com cronologias múltiplas; ou de resultados dramáticos } \\
\text { de experimentos não controlados } \\
\text { Evidência de opiniões de autoridades respeitadas, } \\
\text { baseadas na experiência clínica, estudos descritivos, ou } \\
\text { descrições de comitês de autoridades }\end{array}$ \\
& \\
3 &
\end{tabular}

\section{Objetivos do uso de antibióticos}

A maioria das infecções intra-abdominais, como apendicite aguda, úlcera péptica perfurada, abscesso pancreático, necessita de intervenção cirúrgica ou de drenagem percutânea para resolução do processo infeccioso. O uso de antibióticos, entretanto, é fundamental para reduzir a possibilidade de falha no tratamento através da diminuição na incidência de infecção intra-abdominal persistente ou recurrente. Também reduz a incidência de septicemia, endocardite bacteriana e infecção de ferida operatória.

Os objetivos da antibioticoterapia são a eliminação do microorganismo, redução da chance de recidiva e diminuição do tempo de resolução dos sinais e sintomas infecciosos. Os antimicrobianos devem ser administrados após o início da ressuscitação volêmica com a finalidade de restabelecer a perfusão visceral para que haja melhor distribuição da droga ${ }^{(22,32)}$.

Em algumas situações, como diverticulite aguda não complicada, somente o uso de antibióticos, sem utilização de procedimento invasivo, pode ser suficiente para a resolução do processo inflamatório.

\section{Início do uso de antibióticos}

Os antibióticos são geralmente iniciados quando se suspeita de diagnóstico de infecção intra-abdominal, mesmo antes de se confirmar o diagnóstico ${ }^{(32)}$. Os antibióticos selecionados devem ser baseados nos agentes infecciosos mais prováveis de serem encontrados no local de infecção (bactérias anaeróbicas e bactérias entéricas gram-negativas) e se necessário, modificados após a obtenção do resultado da cultura e antibiograma.

\section{Seleção de antibióticos}

No arsenal de medidas para redução das taxas de infecção cirúrgica, a utilização apropriada do antibiótico exerce papel de destaque. Os antibióticos são prescritos com finalidade profilática ou curativa de um processo infeccioso ${ }^{(13)}$.

A seleção do esquema de antibióticos deve ser baseada: a) no agente infeccioso mais provável, b) na eficácia, c) na segurança (toxicidade e efeitos colaterais, indução de resistência), d) no custo e, e) na comodidade posológica (Quadro 2) ${ }^{(29)}$.

QUADRO 2. Agentes recomendados para o tratamento de infecções intraabdominais comunitárias complicadas

\begin{tabular}{|c|c|c|}
\hline Tipo de terapia & $\begin{array}{l}\text { Infecções leves a } \\
\text { moderadas }\end{array}$ & Infecções graves \\
\hline \multicolumn{3}{|l|}{ Monoterapia } \\
\hline $\begin{array}{l}\text { Beta-lactâmico/associação } \\
\text { com inibidor de beta- } \\
\text { lactamase }\end{array}$ & $\begin{array}{l}\text { Ampicilina/sulbactam; } \\
\text { ticarcilina/ácido clavulânico }\end{array}$ & Piperacilina/tazobactam \\
\hline Carbapenêmicos & Ertapenem & $\begin{array}{l}\text { Imipenem/cilastatina; } \\
\text { meropenem }\end{array}$ \\
\hline \multicolumn{3}{|l|}{ Combinação de agentes } \\
\hline Base de cefalosporina & $\begin{array}{l}\text { Cefazolina ou cefuroxima } \\
\text { mais metronidazol }\end{array}$ & $\begin{array}{l}\text { (cefotaxima, ceftriaxona, } \\
\text { ceftizoxima, ceftazidima, } \\
\text { cefepime) mais metronidazol }\end{array}$ \\
\hline Base de fluoroquinolona & $\begin{array}{l}\text { Ciprofloxacina, } \\
\text { levofloxacina, moxifloxacina } \\
\text { ou gatifloxacina, cada } \\
\text { combinação com } \\
\text { metronidazol }\end{array}$ & $\begin{array}{l}\text { Ciprofloxacina mais } \\
\text { metronidazol }\end{array}$ \\
\hline Base de monobactâmicos & & $\begin{array}{l}\text { Aztreonam mais } \\
\text { metronidazol }\end{array}$ \\
\hline
\end{tabular}

Quanto ao espectro, deve ser escolhido um antibiótico que seja eficaz contra a flora a ser encontrada e que não confronte com a sensibilidade bacteriológica do hospital em questão. A microflora do sítio cirúrgico é variável de hospital para hospital. Hospitais de alta complexidade e com maior número de doentes graves, tendem a apresentar perfil microbiológico mais agressivo e resistente ${ }^{(12)}$. Muitas vezes há necessidade de se associar drogas e, sua farmacocinética é importante para que não sejam utilizados antimicrobianos antagônicos, mas sim sinérgicos. A principal 
condição que favorece a resistência bacteriana é o risco de alteração da flora microbiana. Deve-se conhecer a farmacocinética da droga para a sua utilização correta. A concentração inibitória mínima, meia-vida, metabolização, via de excreção e dose inicial devem ser levadas em consideração ${ }^{(13)}$.

Existem vários esquemas de eficácia comprovada no tratamento das infecções intra-abdominais. O Comitê de Agentes Terapêuticos da Sociedade de Infecção Cirúrgica realizou extensa revisão de artigos publicados sobre o uso de antimicrobianos ${ }^{(21)}$, que foi utilizada pela Sociedade de Infecção Cirúrgica para desenvolver os "guidelines" de terapia antimicrobiana para infecções intra-abdominais ${ }^{(22)}$. Essas normas não consideram abscessos intra-parenquimatosos hepáticos e esplênicos, infecções oriundas do trato genitourinário ou infecções do retroperitônio, com exceção do pâncreas. Excluem-se também infecções em pacientes com idade inferior a 18 anos e peritonite primária ${ }^{(29)}$. Para ratificar recomendações destes "guidelines", utiliza-se um sistema de graduação da SADI (Sociedade Americana de Doenças Infecciosas) (Quadro 1) ${ }^{(19)}$.

\section{Infecções intra-abdominais cirúrgicas comunitárias}

Os agentes infecciosos mais prováveis são a $E$. coli e Bacteroides fragilis. Os esquemas antibióticos mais recomendados são:

a - gentamicina ou ceftriaxona ou fluoroquinolona associado a metronidazol ou clindamicina. A gentamicina é melhor em custo, porém pior em toxicidade (nefrotoxicidade e ototoxicidade). A ceftriaxona apresenta baixo custo e toxicidade, comodidade posológica, porém, com chance maior de induzir resistência. As quinolonas apresentam baixa toxicidade, vantagem nas infecções pélvicas (DST), porém, são as mais caras. O metronidazol é melhor que a clindamicina em eficácia, toxicidade e custo.

b-ampicilina/sulbactam ou amoxicilina/clavulanato ou amoxicilina/sulbactam: vantagem de cobrirem enterococos.

c - cefoxitina: bom para profilaxia e terapia de curta duração. Induz resistência mais freqüentemente que os demais.

$\mathrm{d}$ - ertapenem: novo carbapenêmico como imipenem e meropenem, porém, com comodidade posológica de $1 \mathrm{vez}$ ao dia. Apresenta amplo espectro de ação antibacteriana para cocos gram- positivos (CGP), bacilos gram-negativos (BGN) e anaeróbios. Não é efetivo contra enterococos, MRSA e pseudomonas.

Analisando estes vários esquemas quanto à segurança, eficácia e custo, os melhores antimicrobianos em infecções cirúrgicas intra-abdominais comunitárias são:

1 - ceftriaxona $2 \mathrm{~g}$ ev/dia + metronidazol $500 \mathrm{mg}$ ev 8/8 h: principal vantagem é o custo.

2 -ampicilina/sulbactam ou amoxicilina/clavulanato ou amoxicilina/sulbactam: menor indução de resistência.

\section{Infecções intra-abdominais cirúrgicas hospitalares}

Infecções pós-operatórias (nosocomiais) são causadas por flora bacteriana mais resistente, como Pseudomonas aeruginosa, espécies de Enterobacter, Proteus, Staphylococcus aureus resistentes à meticilina, Enterococcus e espécies de Candida. Para essas infecções, esquemas antibacterianos mais complexos são recomendados.
Infecções por BGN hospitalares como Pseudomonas $e$ enterobactérias resistentes associados a Bacteroides fragilis pode-se utilizar duoterapia ou monoterapia:

a - duoterapia: ceftazidima ou cefepime (grupo "CESP" - que significa Citrobacter, Enterobacter, Serratia e Proteus/ Providencia) ou ciprofloxacino + metronidazol;

$\mathrm{b}$ - monoterapia: piperacilina/tazobactam ou ticarcilina/clavulanato: cobrem enterococos ou também imipenem/cilastatina ou meropenem ou ertapenem (não cobre Pseudomonas).

Os principais gram-negativos hospitalares são:

1 - enterobactérias produtoras de beta-lactamase cromossômico - induzíveis: grupo "CESP" são o Citrobacter, Enterobacter, Serratia, Proteus, Providência e Morganella. São bactérias com potencial de se tornar resistentes na vigência de tratamento com beta-lactâmico. A melhor escolha são as cefalosporinas de quarta geração como o cefepime. Pode-se utilizar fluoroquinolonas se o foco for urinário e carbapenêmicos se os germes forem sensíveis a esses.

2 - enterobactérias produtoras de "ESBL" que significa beta-lactamase de espectro ampliado): o principal germe é a Klebsiella (50\%). São bactérias resistentes à cefalosporinas de terceira geração no antibiograma, porém, sensíveis as de segunda geração. Os carbapenêmicos parecem ser a melhor escolha terapêutica.

\section{Terapia Antifúngica}

Candida albicans ou outros fungos são isolados em aproximadamente $20 \%$ dos pacientes com perfuração aguda do trato gastrointestinal. Até mesmo quando um fungo é identificado, não é necessária terapia antifúngica, a menos que o paciente seja imunodeprimido (neoplasia, transplante ou doenças inflamatórias) ou encontre-se em pós-operatório ou apresente infecção intraabdominal recurrente (categoria $\mathrm{B}$ e grau 2 de recomendação do Quadro 1).

Se a $C$. albicans for encontrada, a escolha apropriada é o fluconazol (categoria B e grau 2 de recomendação do Quadro 1). Para as espécies resistentes a este anti-fúngico, terapia com anfotericina B, caspofungina ou voriconazol é indicada (categoria B e grau 3 de recomendação do Quadro 1). Os dois últimos agentes são mais empregados em pacientes com disfunção renal por apresentarem menor toxicidade que a anfotericina $\mathrm{B}$ (categoria A e grau 1 de recomendação do Quadro 1).

\section{Seleção de antibiótico empírico}

Infecções oriundas do estômago, duodeno, via biliar e delgado proximal podem ser causadas por germes aeróbios gram-positivos e negativos e organismos facultativos. Perfurações do delgado distal podem levar a infecções causadas por organismos aeróbios e facultativos gram-negativos. Anaeróbios, como o B. fragilis, apresentam-se comumente em infecções derivadas do cólon. A Escherichia coli é a bactéria gram-negativa facultativa mais comum encontrada nas infecções intra-abdominais.

Nas infecções comunitárias intra-abdominais, o uso de antibióticos empíricos deve ser contra gram-negativos aeróbios entéricos, bacilos facultativos e cocos gram-positivos betalactâmicos susceptíveis (categoria A e grau 1 de recomendação do Quadro 1). Cobertura contra bacilos anaeróbios obrigatórios é 
necessária nas infecções de delgado distal e cólon e perfurações gastrointestinais mais proximais com obstrução distal (categoria A e grau 1 de recomendação do Quadro 1).

Agentes utilizados para tratamento de infecções nosocomiais em UTIs não devem ser rotineiramente empregados em infecções comunitárias ${ }^{(28,29)}$. Em pacientes com infecções comunitárias leves a moderadas devem ser empregados antimicrobianos de menor espectro como ampicilina/sulbactam, cefazolina ou cefuroxima/ metronidazol, ticarcilina/clavulanato e ertapenem devido ao custo e menor risco de toxicidade (categoria A e grau 1 de recomendação do Quadro 1). Aminoglicosídeos não são recomendados como rotina em infecções comunitárias intra-abdominais (categoria $\mathrm{A} \mathrm{e}$ grau 1 de recomendação da Quadro 1), eles devem ser reservados para pacientes alérgicos a beta-lactâmicos e como segunda escolha nos esquemas de quinolonas.

Complementação do curso de antibióticos com formas orais de quinolona mais metronidazol (categoria A e grau 1 de recomendação da Quadro 1) ou amoxicilina/clavulanato (categoria B e grau 3 de recomendação da Quadro 1) é aceitável em pacientes que toleram dieta via oral ${ }^{(8)}$.

Em pacientes de alto risco (escore de APACHE alto, desnutridos, doenças cardiovasculares, irresponsivos ao controle da infecção, imunodeprimidos como transplantados, neoplasias e doenças inflamatórias) devem ser utilizados esquemas antibióticos de amplo espectro como meropenem, imipenem/cilastatina, piperacilina/ tazobactan, ciprofloxacina mais metronidazol, ou cefalosporinas de terceira ou quarta geração associadas ao metronidazol (categoria $\mathrm{C}$ e grau 3 de recomendação do Quadro 1) ${ }^{(7,10,16,24)}$. Pacientes com permanência hospitalar pré-operatória prolongada (maior que 2 dias) e uso prévio de antimicrobianos podem ser susceptíveis a infecções recurrentes e requerem terapia para infecção nosocomial (categoria C e grau 3 de recomendação do Quadro 1).

A antibioticoterapia para infecções estabelecidas deve ser mantida até a resolução dos sinais clínicos da infecção, incluindo normalização da temperatura e do hemograma e retorno da atividade gastrointestinal. O risco de falha no tratamento é pequeno em pacientes sem evidências de infecção no momento da suspensão do antimicrobiano ${ }^{(26)}$.

Pacientes com evidências clínicas persistentes ou recurrentes de infecção intra-abdominal após 5-7 dias de antibiótico devem ser submetidos a análise diagnóstica com tomografia computadorizada ou ultra-sonografia e mantidos com antibioticoterapia efetiva contra os germes inicialmente identificados (categoria $\mathrm{C}$ e grau 3 de recomendação do Quadro 1).

Em infecções comunitárias intra-abdominais, a flora bacteriana encontrada é quase sempre susceptível aos regimes antimicrobianos recomendados empiricamente, portanto não há necessidade de se realizar cultura e antibiograma de rotina. Por exemplo, nos casos de apendicite gangrenada ou perfurada, vários estudos retrospectivos mostraram que não há benefícios na coleta de culturas locais para a indicação de regimes antimicrobianos ${ }^{(4,20)}$. Porém, para outras infecções, como as de cólon, há maior chance de falha se a antibioticoterapia não for dirigida contra os germes isolados ${ }^{(3,11)}$. Com relação a bactérias anaeróbias, há maior e crescente resistência para a clindamicina, cefoxitina, piperacilina e quinolonas ${ }^{(1,11)}$.
Nas infecções após cirurgias eletivas ou de emergência, a flora encontrada é geralmente mais resistente. Os germes encontrados são similares aos das infecções nosocomiais e os anaeróbios não são encontrados com freqüência. A mortalidade e a falha na resposta terapêutica são maiores se não for iniciada antibioticoterapia empírica contra os germes mais prováveis (categoria $\mathrm{C}$ e grau 3 de recomendação do Quadro 1) ${ }^{(9,23)}$.

Cobertura antimicrobiana de rotina contra Enterococcus não é necessária em infecções intra-abdominais comunitárias (categoria A e grau 1 de recomendação do Quadro 1), porém deve ser realizada, de acordo com os testes de susceptibilidade, naqueles com infecções nosocomiais em que esta bactéria foi identificada (categoria B e grau 3 de recomendação do Quadro 1).

\section{Esquemas de antibióticos não recomendados}

Alguns antibióticos não devem ser utilizados isoladamente pela falta de cobertura antimicrobiana adequada ${ }^{(6)}$. A cefazolina e outras cefalosporinas de primeira geração, penicilina, ampicilina, cloxacilina, eritromicina e vancomicina não devem ser utilizadas empiricamente, a menos que combinadas com outros agentes eficazes, devido a cobertura bacteriana inadequada. Metronidazol e clindamicina não devem ser utilizados isoladamente por não apresentarem cobertura adequada contra bactérias entéricas facultativas. Aminoglicosídeos, aztreonam, polimixinas, cefotaxima, ceftriaxona e ceftazidima também não devem ser utilizados isoladamente por não apresentarem atividade anaerobicida adequada.

O cloranfenicol e moxalactam devem ser evitados pela possibilidade de complicações graves, como anemia aplástica e hemorragia, respectivamente.

\section{Duração da antibioticoterapia}

Os antibióticos devem ser utilizados nas infecções intraabdominais (peritonites e abscessos) até a normalização da temperatura e do leucograma e a melhora das manifestações clínicas de infecção (inapetência, náuseas, vômitos, íleo paralítico e febre). Se não houver melhora clínica ou o paciente persistir com febre, leucocitose e ou bastonetose por mais de 5 dias, deve-se considerar a possibilidade de abscesso não drenado, presença de infecção extra-abdominal ou resistência aos antibióticos. Outras causas de febre, como tromboflebite e efeitos colaterais dos antibióticos também devem ser considerados. A suspensão da antibioticoterapia enquanto o paciente tem febre ou leucocitose aumenta o risco de recurrência ou persistência de infecção intra-abdominal ${ }^{(26,29)}$.

\section{Condições especiais \\ Apendicite aguda}

Nas fases mais iniciais da apendicite aguda (apendicite catarral e apendicite supurativa, mas sem abscesso), a administração de antibióticos deve ser profilática e deve ser iniciada no préoperatório e suspensa assim que o cirurgião determinar que não ocorreu gangrena do apêndice ou formação de abscesso. Nessas duas últimas situações, os antibióticos devem ser administrados terapeuticamente, de maneira igual à descrita anteriormente para as outras infecções intra-abdominais. Em pacientes que serão 
tratados em regime ambulatorial e não hospitalar, antibioticoterapia oral contra $E$. coli e $B$. fragilis pode ser usada ${ }^{(6,25)}$.

\section{Perfuração do trato gastrointestinal alto}

A administração de antibióticos deve ser de até 24 horas nas lesões intestinais devido a trauma penetrante, fechado ou iatrogenia, que são corrigidos dentro de 12 horas e com contaminação do campo operatório por conteúdo enteral (categoria A e grau 1 de recomendação do Quadro 1). O emprego de antibióticos também deve ser profilático nas perfurações agudas do estômago, duodeno e jejuno proximal na ausência de terapia antiácida ou neoplasia maligna (categoria B e grau 2 de recomendação do Quadro 1) ${ }^{(5,14)}$. Nas perfurações com mais de 24 horas de evolução, deve-se utilizar antibioticoterapia, geralmente uma combinação de cefalosporina de terceira geração com metronidazol.

\section{Colecistite aguda}

É freqüentemente uma entidade inflamatória e não-infecciosa. Se infecção for suspeitada, antibioticoterapia deve ser iniciada contra Enterobacteriaceae (categoria B e grau 2 de recomendação do Quadro 1) ${ }^{(30,31)}$. A Escherichia coli é agente infeccioso mais freqüente. Cobertura contra anaeróbios também está indicada. $\mathrm{Na}$ presença de colecistite aguda não complicada, antibióticos de largo espectro, geralmente uma combinação de cefalosporina de terceira geração com metronidazol, devem ser iniciados no pré-operatório e suspensos no pós-operatório imediato. Na presença de complicações, como empiema, gangrena, perfuração e fístula, os antibióticos devem ser continuados conforme as condições clínicas.

\section{Pancreatite aguda}

A incidência de infecção pancreática e de tecidos peripancreáticos na pancreatite aguda depende da sua gravidade. É praticamente inexistente na forma edematosa e ocorre em cerca de $50 \%$ das pancreatites necróticas. A infecção geralmente se desenvolve após 2 semanas do início da pancreatite aguda. BERGER et al. ${ }^{(2)}$ relataram presença de infecção pancreática em $24 \%$ dos pacientes operados nos primeiros 7 dias e $71 \%$ dos operados na terceira semana. Quando ocorre infecção, a flora identificada é quase sempre colônica, sendo a Escherichia coli a bactéria mais comum $^{(2,19)}$. Pseudomonas, Klebsiella e Enterococcus também são comuns ${ }^{(26)}$. Presença de fungo ocorre em até $40 \%$ dos pacientes com infecção pancreática ${ }^{(19)}$. Punção percutânea orientada por tomografia é um método seguro e eficaz para distinguir pancreatite infectada de não-infectada. O diagnóstico de infecção pancreática ou peripancreática requer desbridamento ou drenagem das coleções e, nestas circunstâncias, terapia antimicrobiana deve ser administrada e continuada até que ocorra melhora clínica e laboratorial. A escolha inicial da droga a ser utilizada deve ser baseada no gram e na cultura do tecido infectado ou fluido colhido na aspiração percutânea ou cirurgia ${ }^{(6)}$.

O uso de antibióticos na prevenção de infecção pancreática e de tecidos peripancreáticos na pancreatite aguda permanece controverso. Antibióticos não estão indicados na forma edematosa. Entretanto, seu uso é geralmente recomendado nas formas mais graves da pancreatite aguda para evitar complicações sépticas. A conclusão de duas meta-análises de estudos controlados foi de que antibioticoprofilático reduz a mortalidade da pancreatite aguda grave $\mathrm{e}^{(17,18,27)}$. O esquema de antibioticoprofilático mais utilizado é uma combinação de cefalosporina de terceira geração ou quinolona com metronidazol ${ }^{(15,19)}$. Se o paciente com infecção diagnosticada tiver sido previamente tratado com antibiótico, a infecção deve ser considerada nosocomial (categoria B e grau 3 de recomendação do Quadro 1).

\section{Falha Terapêutica}

Se a infecção abdominal persistir, a causa usual deve ser um foco de infecção que requeira drenagem. Falha clínica precisa ser suspeitada quando não há resolução da febre, leucocitose e íleo até o terceiro ou quarto dia de pós-operatório. Doença persistente ou recurrente exige investigação de um foco drenável de infecção no abdome, incluindo exames de imagem. Se um ou mais microorganismos isolados não forem sensíveis aos antibióticos administrados, está indicada sua troca por agentes antimicrobianos de maior espectro ou de acordo com culturas colhidas ${ }^{(6)}$.

Coelho JCU, Baretta GAP, Okawa L. Selection and use of anti-infective agents for intra-abdominal infections. Arq Gastroenterol 2007; 44(1):85-90.

ABSTRACT - Background - Intra-abdominal infections are common and are associated with elevated morbidity and mortality. The microorganisms that cause intra-abdominal infections are usually from the gastrointestinal flora, mainly E. coli and Bacteroides fragilis. Aim - To present a review of the selection and use of antibiotics in intra-abdominal infections. Conclusions - Appropriate use of antibiotics is essential to control infection and to reduce treatment failure. Antibiotics are initiated whenever intra-abdominal infection is suspected and the antimicrobial agents are selected based on the most common microorganisms involved. In addition, efficacy, cost, safety, and posologic regimen are considered for an appropriated selection. Antibiotic regimen is different whether the infection is acquired in the community or at hospital due to the more resistant flora in the latter.

HEADINGS - Abdomen. Infection. Cross infection. Anti-bacterial agents. 


\section{REFERÊNCIAS}

1. Aldridge KE, O'Brien M. In vitro susceptibilities of the Bacteroides fragilis group species: change in isolation rates significantly affects overall susceptibility data. J Clin Microbiol. 2002;40:4349-52.

2. Beger HG, Bittner R, Block S, Büchler M. Bacterial contamination of pancreatic necrosis. A prospective clinical study. Gastroenterology. 1986;91:433-8.

3. Berne TV, Yellin AW, Appleman MD, Heseltine PN. Antibiotic management of surgically treated gangrenous or perforated appendicitis: comparison of gentamicin and clindamycin versus cefamandole versus cefoperazone. Am J Surg. 1982;144: 8-13.

4. Bilik R, Burnweit $\mathrm{C}$, Shandling B. Is abdominal cavity culture of any value in appendicitis? Am J Surg. 1998;175:267-70.

5. Boey J, Wong J, Ong GB. Bacteria and septic complications in patients with perforated duodenal ulcers. Am J Surg. 1982;143:635-9.

6. Bohnen JMA, Solomkin JS, Dellinger EP, Bjornson HS, Page CP. Guidelines for clinical care: anti-infective agents for intra-abdominal infection. A surgical infection society policy statement. Arch Surg. 1992;127:83-9.

7. Brook I. Intra-abdominal, retroperitoneal, and visceral abscesses in children. Eur J Pediatr Surg. 2004;14:265-73.

8. Cohn SM, Lipsett PA, Buchman TG, Cheadle WG, Milsom JW, O'Marro S, Yellin AE, Jungerwirth S, Rochefort EV, Haverstock DC, Kowalsky SF. Comparison of intravenous/oral ciprofloxacin plus metronidazole versus piperacillin/tazobactam in th treatment of complicated intra-abdominal infections. Ann Surg. 2000;232:254-62.

9. Cruse JPE. Postoperative study of 20,105 surgical wounds with emphasis on the use of topical antibiotics and prophylactic antibiotics. Presentation at Fourth Symposium on Control of Surgical Infections, American College of Surgeons, Washington D.C. 10 November, 1972.

10. Dellinger EP, Wertz MJ, Meakins JL, Solomkin JS, Allo MD, Howard RJ, Simmon RL. Surgical infection stratification system for intra-abdominal infection. Multicente trial. Arch Surg. 1985;120:21-9.

11. Falagas ME, Barefoot L, Griffith J, Ruthazar R, Snydman DR. Risk factors leading to clinical failure in the treatment of intra-abdominal or skin/soft tissue infections. Eur J Clin Microbiol Infect Dis. 1996;15:913-21.

12. FELAC - Federação Latino Americana de Cirurgia. Antimicrobianos: antibióticos profiláticos. In: FELAC. Ferida e infecção cirúrgica. Bogotá, Colômbia; 2001. p. 287-300.

13. Ferraz EM, Ferraz AAB. Antibioticoprofilaxia. In: Ferraz EM, editor. Infecção em cirurgia. Rio de Janeiro: Medsi; 1997. p.345-52.

14. Fong IW. Septic complications of perforated peptic ulcer. Can J Surg. 1983;26:370-2.

15. Garg PK, Khanna S, Bohidar NP, Kapil A, Tandon RK. Incidence, spectrum and antibiotic sensitivity pattern of bacterial infections among patients with acute pancreatitis. Gastroenterol Hepatol. 2001;16:1055-9.

16. Gleisner AL, Argenta R, Pimentel M, Simon TK, Jungblut CF, Petteffi L, de Souza RM, Sauerssig M, Kruel CD, Machado AR. Infective complications according to duration of antibiotic treatment in acute abdomen. Int J Infect Dis. 2004;8:155-62.

17. Gloor B, Schmidt O, Uhl W, Buchler NW. Prophylactic antibiotics and pancreatic necrosis. Curr Gastroenterol Rep. 2001;3:109-14.

18. Golub R, Siddiqi, Pohl D. Role of antibiotics in acute pancreatitis: a meta-analysis J Gastrointest Surg. 1998;2:496-505.
19. Kish MA. Guide to development of practice guidelines. Clin Infect Dis. 2001;32:851-4

20. Kokoska ER, Silen ML, Tracy TF, Dillon PA, Kennedy DJ, Cradock TV, Weber TR. The impact of intraoperative culture on treatment and outcome in children with perforated appendicitis. J Pediatr Surg. 1999;34:749-53.

21. Mazuski JE, Sawyer RG, Nathens AB, DiPiro JT, Schein M, Kudsk KA, Yowler C, Therapeutic Agents Committee of the Surgical Infections Society. The Surgical Infection Society guidelines on antimicrobial therapy for intra-abdominal infections: an executive summary. Surg Infect (Larchmt). 2002;3:161-73.

22. Mazuski JE, Sawyer RG, Nathens AB, DiPiro JT, Schein M, Kudsk KA, Yowler C, Therapeutic Agents Committee of the Surgical Infections Society. The Surgical Infection Society guidelines on antimicrobial therapy for intra-abdominal infections: evidence for the recommendations. Surg Infect (Larchmt). 2002;3:175-233.

23. Montravers P, Gauzit R, Muller C, Marmuse JP, Fichelle A, Desmonts JM. Emergence of antibiotic-resistant bacteria in cases of peritonitis after intra-abdominal surgery affects the efficacy of empirical antimicrobial therapy. Clin Infect Dis. 1996;23:486-94.

24. Oztoprak N, Cevik MA, Akinci E, Korkmaz M, Erbay A, Eren SS, Balaban N, Bodur H. Risk factors for ICU-acquired methicillin-resistant Staphylococcus aureus infections. Am J Infect Control. 2006;34:1-5.

25. Polk HC Jr, Lopez-Mayor JF. Postoperative wound infections: a prospective study of determinant factors and prevention. Surgery. 1969;66:97-103.

26. Rau B, Pralle U, Mayer JM, Beger HG. Role of ultrassonographically guide fineneedle aspiration cytology in the diagnosis of infected pancreatic necrosis. Br J Surg. 1998;85:179-84.

27. Sharma VK, Howden CW. Prophylactic antibiotic administration reduces sepsis and mortality in acute necrotizing pancreatitis: a meta-analysis. Pancreas. 2001;22:28-31.

28. Shlaes DM, Gerding DN, John JF, Craig WA, Bornstein DL, Duncan RA, Eckman MR, Farrer WE, Greene WH, Lorian V, Levy S, McGowan JE, Paul SM, Ruskin J, Tenover FC, Watanakunakorn C. Society for Healthcare Epidemiology of America and Infectious Diseases Society of America Joint Committee on the Prevention of Antimicrobial Resistance: guidelines for the prevention of antimicrobial resistance in hospitals. Clin Infect Dis. 1997;25:584-99.

29. Solomkin JS, Mazuski JE, Baron EJ, Sawyer RG, Nathens AB, DiPiro JT, Buchman T, Dellinger EP, Jernigan J, Gorbach S, Chow AW, Bartlett J. Guidelines for the selection of anti-infective agents for complicated intra-abdominal infections. Clin Infect Dis. 2003;37:997-1005.

30. Taylor E, Berjis A, Bosch T, Hoehne F, Ozaeta M. The efficacy of postoperative oral antibiotics in appendicitis: a randomized prospective double-blinded study. Am Surg. 2004; 70:858-62.

31. Westphal JF, Brogard JM. Biliary tract infections: a guide to drug treatment. Drugs. 1999;57:81-91.

32. Wilson SE, Turpin RS, Hu XH, Sullivan E, Mansley EC, Ma L. Does initial choice of antimicrobial therapy affect length of stay for patients with complicated intra-abdominal infections? Am Surg. 2005;71:816-20. 


\section{MESACOL ${ }^{\circledR}$}

USO ADULTO

Apresentaçōes e composição:

(a) 30 comprimidos revestidos, contendo $400 \mathrm{mg}$ de mesalazina; embalagens com 30 comprimidos revestidos contendo $800 \mathrm{mg}$ de mesalazina. Cada comprimido contém lactose, amidoglicolato
de sódio, estearato de magnésio, talco, polividona, silica anidra coloidal, ácido metacrilico copolímero tipo B, dibutilftalato, óxido de ferro amarelo, óxido de ferro vermelho e polietilenoglicol 6000 . Supositórios: Embalagens
com 10 supositórios contendo $250 \mathrm{mg}$ de mesalazina; embalagens com 10 supositórios contendo $500 \mathrm{mg}$ de mesalazina Cada supositório contém mistura de glicérides de ácidos graxos saturados.

Indicações: Mesacol está indicado como antiinflamatório de ação local no tratamento de doenças inflamatórias intestinais, na fase aguda e na prevenção ou redução das recidivas destas enfermidades: retocolite ulcerativa Contra-indicaçōes: Hip

supositório Insuficiências hepáticae renal graves e aos componentes da formula de Mesacol comprimido o úlcera gástrica e duodenal ativa; tendência elevada a sangramento.

Crianças abaixo de 2 anos

Precauções e advertências: Assim como todos os salicilatos, a mesalazina deve ser utilizada com cautela em paciente com úlceras gástricas ou duodenais e por pacientes asmáticos (em função das reações de hipersensibilidade). cujos niveis sangüineos de uréia ou proteinúria estejam aumentados. A mesalazina ér rapidamente excretada pelos rins, principalmente o seu metabólito ácido $\mathrm{N}$-acetil-5-aminosalićlico. Em ratos, altas doses de mesalazin administradas por via IV, causaram toxicidade tubular e glomerular. Em caso de aparecimento de disfunção rena durante o tratamento deve-se suspeitar de nefrotoxicidade induzida pela mesalazina. Nestes casos é recomendad monitorar a função renal, especialmente no início do tratamento. Durante tratamento prolongado, é também necessário monitorar regularmente a função renal (creatinina sérica). O produto, a princípio, não deve ser empregado èm gestantes e lactantes, exceto quanalo absolutamente necessario. O risco teorico de kernicterus relacionado evidência de efeitos teratogênicos ou de toxicidade fetal oriundos da mesalazina. A pequena experiência de uso da mesalazina durante a gravidez não mostrou efeito prejudicial ao feto; entretanto, a mesalazina deve ser usada com cautela durante a gravidez e somente quando os benefícios para a mãe forem superiores aos riscos potencials ao feto.Baixas concentraçoes de mesalazina e de seu metabólito $\mathrm{N}$-acetilado foram detectadas no leite materno. mas o significado clinico desta evidencia ainda náo foi determinado. Portanto, deve-se ter cautela na administraçá da mesalazina a lactantes.A da naientá estabeleciêa a segurança do produto emi crianças. O produto contèn Interações medicamentosas: A ação hipoglicemiante das sulfoniluréias pode ser intensificada, assim como hemorragia gastrointestinal causada por cumarínicos. A administração oral da mesalazina pode potencializar a toxicidade do metotrexato. O efeito uricosúrico da probenecida e sulfimpirazona pode ser diminuído, assim
como a ação diurética da furosemida e da espironolactona. A ação tuberculostática da rifampicina tambén pode ser diminuída. Em tese, a administração concomitante de anticoagulantes orais deve ser feita com cautela Substâncias como a lactulose, que diminuem o pH do cólon, podem reduzir a liberação da mesalazina dos comprimidos revestidos de Mesacol.
Reações adversas: As reações adversas ocorrem em uma pequena proporção de pacientes que, previamente, não toleraram a sulfassalazina, tais como náuseas, diarréia, vômitos, dor abdominal, cefaléia e flutuações do humor.Têm sido relatadas reactoct úpus eritematoso, rashes e artralgia. Estes efeitos ocorrem independentemente da dose administrada. Pode haver aumento dos níveis de metahemoglobina. Mesacol pode estar associado com a exacerbação dos casos de com o tratamento por via oral; geralmente estes sintomas regridem com a suspensão do tratamento. Há a, hepatite e discrasias sangüíneas, tais como leucopenia, neutropenia, trombocitopenia e anemia aplástica.

Posologia e modo de usar:
Comprimido: A dose recomendada para adultos é de $800-2400 \mathrm{mg}$ por dia, igualmente dividida a critério médico na dependência da gravidade do caso. Nos casos mais graves a posologia pode ser aumentada para $4.800 \mathrm{mg}$ ao dia. De forma
Colite ulcerativa

- Indução da remissão: dose de $2.400-4.800 \mathrm{mg}$

- Manutenção da remissão: dose de 1.200 - $2.400 \mathrm{mg}$ podendo ser aumentada para $4.800 \mathrm{mg}$

Doença de Crohn

Manutenção da remissão: dose de 2.400 mg

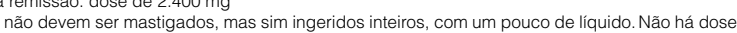
ecomendada para crianças

250 e 500 mg: Os supositórios são utilizados para tratamento da proctite e da proctosigmoidite. A dose recomendada para adultos é de $1-2$ supositórios de $500 \mathrm{mg}$ ou 2 a 4 de $250 \mathrm{mg}$, até 3 vezes ao dia, apos a defecaçăo. A dose depende da gravidade da doença, e pode ser diminuída assim que houver melhora lenta à terapia oral, recomenda-se $1-2$ supositórios de $500 \mathrm{mg}$, pela manhã e à noite, como adjunto da terapia oral. Não há dose recomendada para crianças. Com a remissão da sintomatologia clínica, preconiza-se como Conduta na superdose

ose e uso em pacientes idosos: Em vista das propriedades farmacocinéticas da substância. Contudo, há falta de dados clínicos sobre superdose cós a ingestão de grande quantidade da considerando-se os possiveis eventos adversos sobre superdose com a mesalazina. Deve-se ter coutela, mesmos sintomas relacionados à intoxicação por salicilatos, tais como: acidose ou alcalose, hiperventilação,

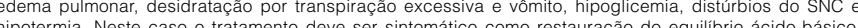
hidratacão do paciente o adminintração de glicose Na eventualidade da administração acidental de doses muito acima das preconizadas recomenda-se lavagem gastrica e administração intravenosa de eletrólitos para promover a diurese. Não há antídoto específico. Mesacol deve ser administrado com cautela em

pacientes idosos (acima de 65 anos).
PRODUTO DE USO SOB PRESCRICCÁO MÉDICA
AO PERSISTIREM OS SINTOMAS O MÉDICO DEVERÁ SER CONSULTADO

Registro MS - 1.0639 .0200
Re

Registro MS - 1.0639 .0200
ME00B1198-02A versão 12-08-03

\section{PLANTABEN ${ }^{\circledR}$}

(ispaghula hus

Medicamento Fitoterápico

USO ADULTO E EM CRIANÇAS ACIMA DE 6 ANOS

Apresentações e composição: Pó efervescente para administração por via oral após dissolução em água

Indicações : doenças que evoluem com alternância de episódios de diarréia e constipação intestinal (intestino
irritável, diverticulose). Regulação da evacuação em pacientes portadores de ânus artificial (colostomia). Constipação intestinal crônica hăa da evacuação em pacientes portadores de ânus artificial (colostomia). alteraçőes de dieta, viagens ou tratamentos prolongados com laxantes potentes. Diarréias de origem funciona e como adjuvante em casos de doença de Crohn. Processos proctológicos como hemorróidas, fissuras anais ou abscesso anal, com redução da dor de defecação e facilitação da evacuação das fezes, por apresentarem maior quantidade de água. Nos casos de ingestão insuficiente de fibras. Complemento da ingestão diária de
fibras, como em dietas de emagrecimento. Distúrbios metabólicos como hiperlipemia e diabetes, no tratamento coadjuvante da terapêutica formal. Diminuiçaao do risco de coronariopatias causadas pelas hiperlipemias. Contra-indicaçōes: obstrução intestinal ou hipersensibilidade ao Plantago ovata.

Precauções: não administrar quando houver dor abdominal, náuseas ou vômitos. Deve-se ter a consciência da importância de hidratação adequada, especialmente se o medicamento foi ingerido sem prévia dissolução em água. Reações adversas: no início do tratamento e dependendo da dose podem ocorrer alguns distúrbios, com administração. Em certos casos, dor abdominal ou diarréia

Interações medicamentosas: não se recomenda administração a pacientes em tratamento com digitálicos. Não administrar junto com antidiarréicos e produtos inibidores da motilidade intestinal (difenoxilato, loperamida

opiáceos, etc) sob risco de obstrução intestinal.
Posologia: Adultos: 1 envelope dissolvido em água, 1 a 3 vezes por dia. Crianças entre 6 a 12 anos: Meio envelope dissolvido em água, 1 a 3 vezes por dia. Crianças acima de 12 anos: 1 envelope dissolvido em água, 1 a 3 vezes por dia

Recomendações para a administração do produto: esvaziar o conteúdo de um envelope em um copo $e$ completar aproximadamente até a metade $(150 \mathrm{ml})$ com água fria. Mexer vigorosamente, com o uso de uma colher, ate que a mistura fique uniforme e, apos finalizada a efervescência, tomar imediatamente. A medicação apetite. Durante o tratamento, recomenda-se a ingestão de 1 a 2 litros de água por dia. Para maiores informaçōes obre o modo de usar, vide bula.

Superdose e pacientes idosos: não foram descritos casos de intoxicação por superdose em virtude de os princípios ativos dessa formulação não serem absorvidos. No entanto, em caso de ingestão excessiva, ao uso do produto por pacientes idosos.

AO PERSISTIREM OS SINTOMAS O MÉDICO DEVERÁ SER CONSULTADO

Registro MS -1.0639 .0205$

Informaçōes completas para prescrição: vide bula
PLO0MO000-02A versă 20.0602 